\title{
DAYLIGHT MODELLING AND ANALYSIS REDUCES INSTALLATION AND OPERATIONAL COSTS OF LIGHTING FOR TUNNEL BR 21 IN BRISBANE, AUSTRALIA
}

\author{
RICHARD A. MORRISON \\ Jenarick Consulting and LVX Group, Brisbane, Australia
}

\begin{abstract}
Urban Transport Design must cater for an ever-increasing population of vehicles in the modern world. Increasingly more complex interchanges are created to enable the flow of mankind in, through and under cities. These complex structures include normal roads, motorways, underpasses and tunnels. As these necessary interchanges increase in size and scale, so too does the need for lighting. The resulting sky glow is evidence of wasted energy. The amount and type of lighting is dictated by the requirements of standardised codes of practice, designed to ensure safety and reduce risk to the authorities in charge, and the drivers themselves. Within these standards can be found guides for the application of daylight which are often overlooked. Reducing the need for lighting assists in reducing sky glow, and the consumption of energy and resources. In this paper, 4D modelling of daylight $(3 \mathrm{D}+$ time $)$ is used to reduce the requirement for lighting in an Urban Transport Tunnel by over $40 \%$. The full extent of available daylight across a calendar year under worst case and best case scenarios is modelled to ensure that all seasonal effects are considered. Utilising the lowest mean average of available light on the carriageway indicates the minimum reduction available to the designer. More complex modelling then allows to further dim the lighting system. This paper demonstrates the techniques used in 4D daylight modelling and proves that the methodology can be used to reduce consumption of lighting energy, installation infrastructure and cost. Additional case histories demonstrate that the savings are available in any geometry or location.
\end{abstract}

Keywords: tunnel lighting, transport lighting design, $4 D$ modelling, daylight analysis, daylight harvesting.

\section{INTRODUCTION}

Streets, roads, underpasses and tunnels, require illumination to provide for the safety of drivers and pedestrians. This case study describes (or case studies) the application of natural light in tunnel entries for the purpose of saving energy, reducing cost of installation of lighting and lifelong maintenance. In order to understand the case study, the underlining methods of tunnel lighting are explained in brief.

Illumination of underpasses and tunnels is especially elaborate, expensive and resource intensive. The reason for this is that high levels of light are needed in the entry to prevent the 'black hole' effect [1], [2]. Back-hole effect refers to the performance of the human visual system when entering a dark space from a bright space. The eye has to adapt to the dark and this takes 9 to 15 minutes [1,] [3], [4]. The lighting operates during the day to reduce the black hole. Without lighting, this time is a period of blindness. Imagine driving at full speed when blinded. It is obvious that this leads to accidents and disaster. These sorts of disasters are exactly why lighting is added to underpasses and tunnels.

The application of lighting in the entries of tunnels and underpasses is prescribed in all international tunnel lighting design standards. The Australasian standard is AS NZS 1158.5 (2014) Lighting for roads and public spaces Part 5: Tunnels and underpasses [1]. The amount of lighting is a function of the brightness perceived by the driver in the access zone from a 


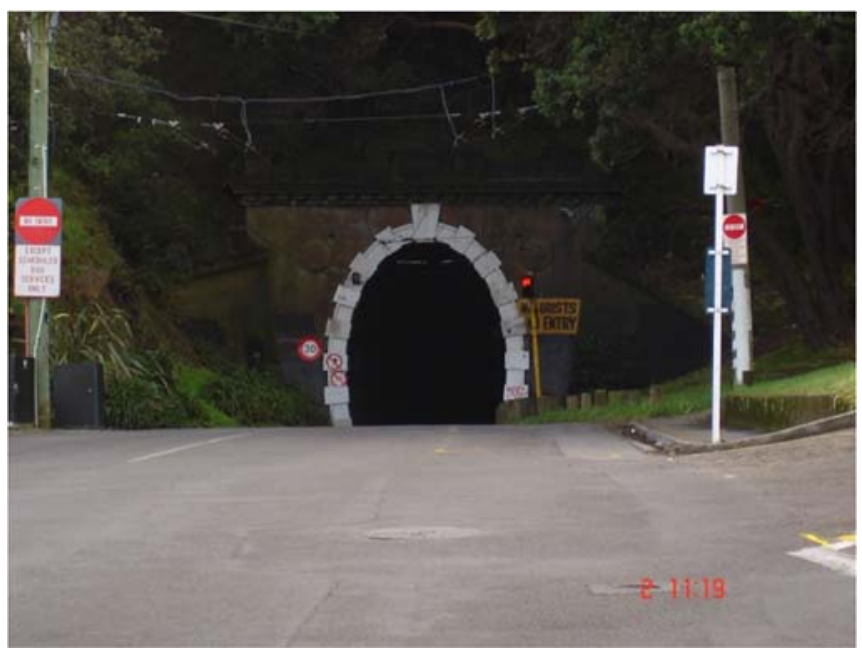

Figure 1: Example of Black Hole effect. Haitaiti tunnel in Wellington, New Zealand. (Source: Morrison, 2011.)

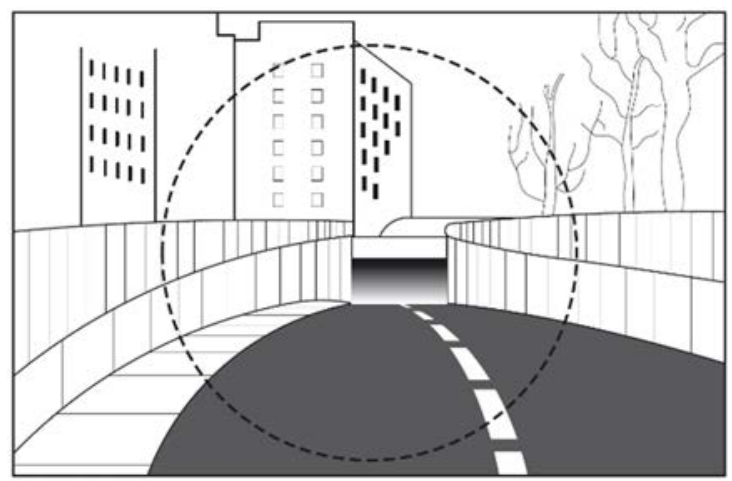

Figure 2: This schematic represents the motorist's $20^{\circ}$ cone of view of the portal from the SSD. The calculated brightness in this field of view is called the L20 [1], [2].

position equal to the Safe Stopping Distance (SSD) in front of the entry. The driver's eye perceives a cone of view measuring 20 degrees, and this is called the L20. The brightness perceived by the driver is calculated using a complex diagram and formula set out in the lighting standards and this maps all the objects in the field of view in order to establish the brightness of the observed scene [1], [5].

The quantity of interior floodlighting is then designed to provide approximately $5-6 \%$ of the L20 for a distance of $1 / 2$ of an SSD from the threshold of the entry. This is called the Threshold Luminance (Lth) [1], [5], [6]. After the initial 1/2 SSD the lighting is then reduced incrementally according to a formula that matches the eyes adaptation response for a distance equal to 20 seconds travel at the posted speed. This is about 440 meters when travelling at 80 kilometres per hour. 


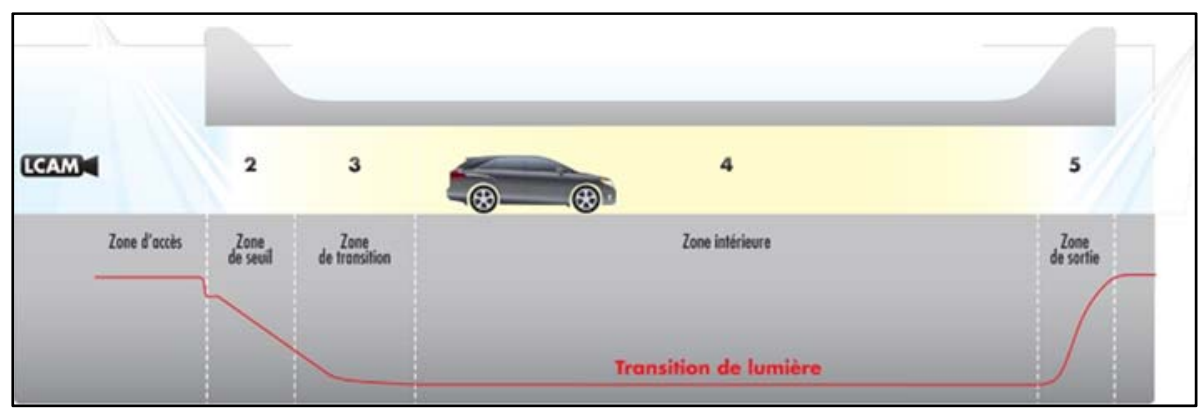

Figure 3: Example by cross section of the lighting level transitions through a tunnel. (Source: NYX Hemera Technologies [2].)

As the light level changes in the access zone, due to season, time of day or weather, specialised photometers measure the change and switch or dim the tunnel lighting accordingly. Daylight measured in the access zones in the southern hemisphere often provide light levels inside the Threshold of 3,000 to 10,000 lux. This size of lighting level requires a very large number of tunnel light fittings as well as the equipment required to hold them up and run and operate them [3], [6].

A typical example from Australia is the Eastern Busway Tunnel in Brisbane [3] which is a $400 \mathrm{~m}$ long tunnel with a power consumption of 300 kilowatts. The tunnel lighting system cost $\$ 5$ million to install. If the tunnel lighting was operated for 6 hours per day at a cost of 25 cents per kilowatt hour, the cost per year would be $\$ 164,250.00$ per annum. This figure is provided only as an example of the scale of cost involved. Any technique that reduces the financial burden of operating a tunnel lighting system is welcomed by the owners. In recent years new technology has offered some energy saving alternatives for lighting hardware (including LED equipment) as well as for lighting controls. However, one method for reducing cost is the application of daylight harvesting to reduce the commitment of electrical systems to provide lighting [3], [4], [6]. To understand tunnel lighting, the methodology is explained in Section 2, and then the argument for harvesting daylight is provided.

\section{TUNNEL LIGHTING}

\subsection{Methodology}

The methodologies of designing tunnel lighting are outlined in the Australian Standard AS NZS 1158.5 (2015) Lighting for roads and public spaces Part 5: Tunnels and underpasses [1]. The methodologies are very similar in all standards including CIE 88. A complex process, the method is based upon the see-through percentage and length of the underpass or tunnel.

The See-through Percentage (STP) is the percentage of the exit portal that can be seen by a motorist at the stopping sight distance from the entrance portal. If there is see through percentage and the structure is less than $125 \mathrm{~m}$ long it is classified as an Underpass and depending upon the percentage of see through various levels of daytime lighting is required. In this case if the structure is greater than $125 \mathrm{~m}$ long then it is classified as a Tunnel, and not an underpass, and the amount of daytime lighting follows the complex methods outlined for tunnels. If there is no see through percentage and the structure is greater than $75 \mathrm{~m}$ long, then 
it is classified a tunnel. In this case if it is less than $75 \mathrm{~m}$ long then partial daytime lighting is called for. The determination of the STP is provided in Fig. 4 below.

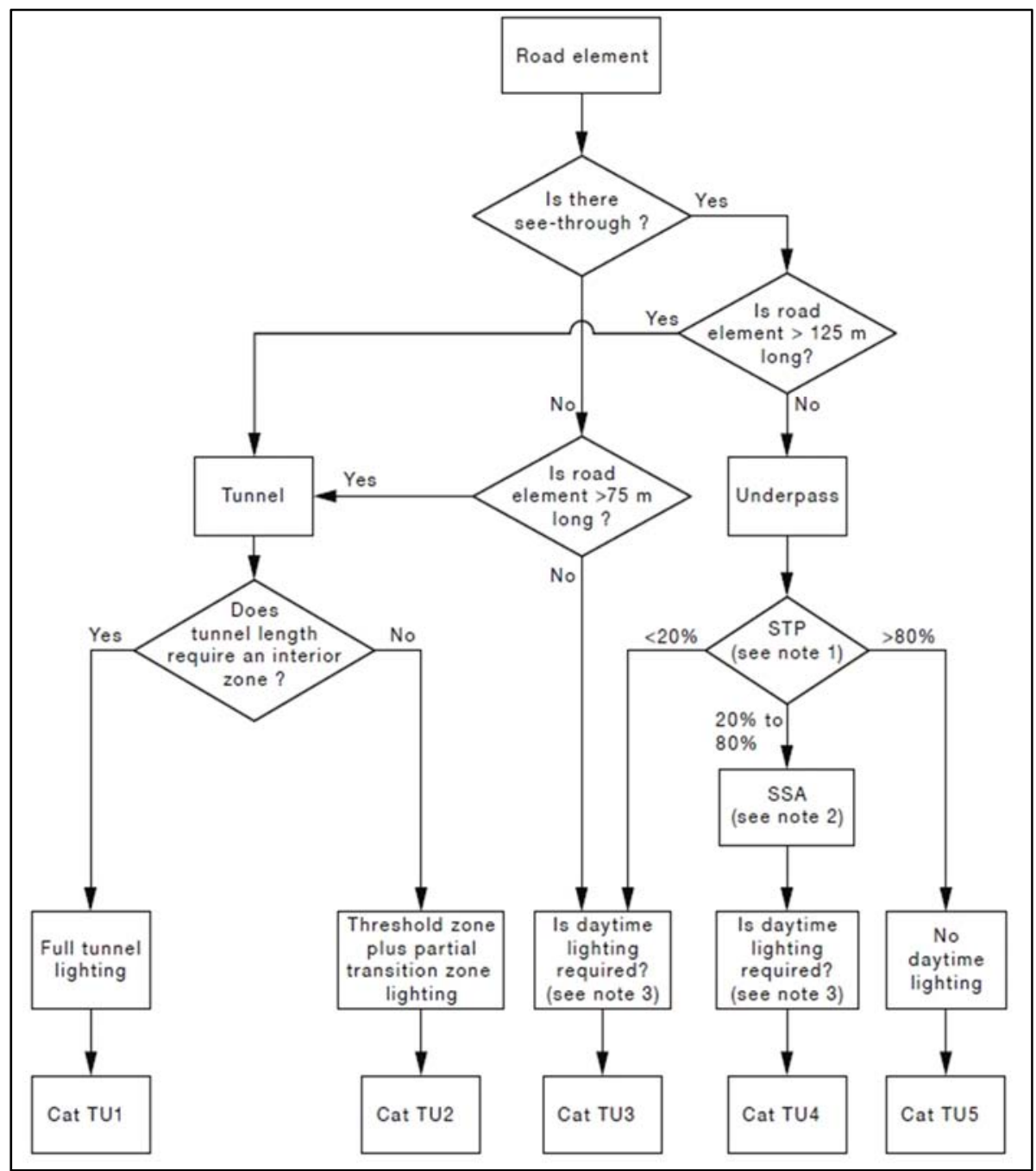

Figure 4: Extract from AS NZS 1158.5 (2014), diagram of the process of determining the lighting scheme required in a tunnel of underpass. Notes: (1) STP (see-through percentage): the percentage of the exit portal that can be seen by a motorist at the stopping sight distance from the entrance portal (see Clause 1.4.19 and Appendix D). (2) SSA (specific situation analysis): for the need and extent of lighting for the specific situation (see Paragraph D2, Appendix D). (3) There may be sufficient daylight penetration to supplement or avoid the installation of daytime lighting. Further guidance is provided in Paragraph D2.3, Appendix D. (Source: Standards Australia [1].) 


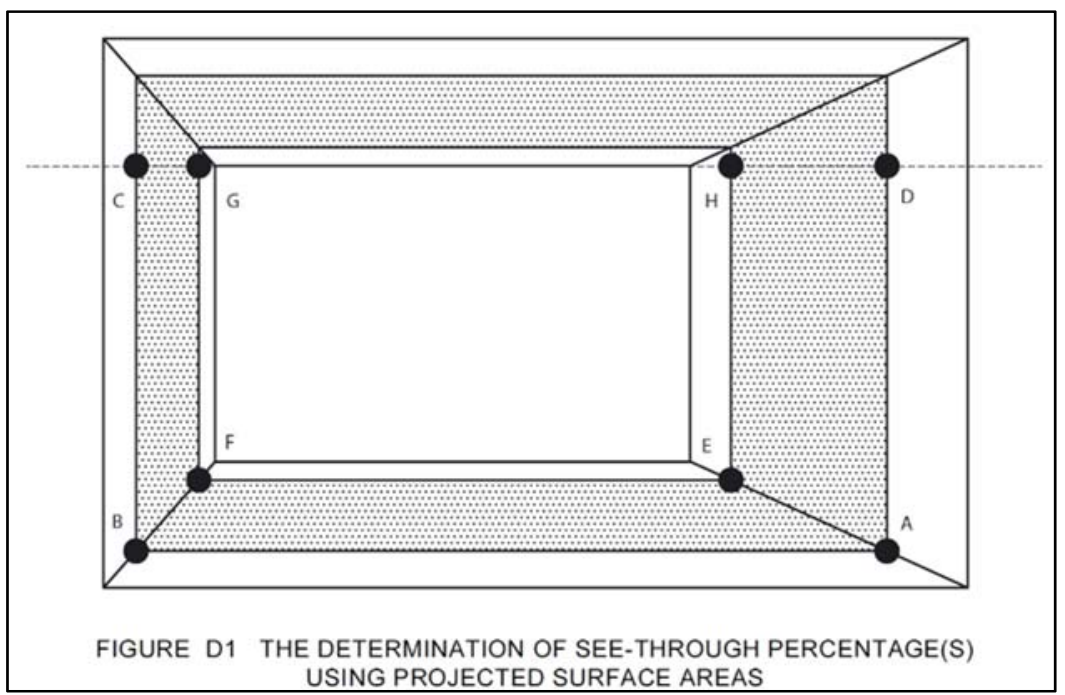

Figure 5: Extract from AS NZS 1158.5 (2014), diagram of the process of determining the STP of a tunnel or underpass. (Source: Standards Australia [1].)

As seen in Fig. 3, if the STP is between $20 \%$ and $80 \%$ then the tunnel or underpass is classified as a TU4, and a Specific Situation Analysis (SSA) is called for. This process calculates the percentage of a critical object representing a car, pedestrian or cyclist that can be seen against the exit portal. The need for daytime lighting is as per the percentage of critical object visibly. In section 4.3.3 of AS NZS 1158.5, the lighting for a TU3 tunnel is prescribed as requiring $50 \%$ of full threshold lighting. In the case of an SSA for a TU4 tunnel, the need for lighting is decided if the critical object is obscured from view in the portal. Quoting from the standard, in [1]. Supplementary daytime lighting shall be provided if:

a) Less than $30 \%$ of the critical object representing a car can be seen against the apparent exit portal; or

b) Less than $50 \%$ of the critical object representing a pedestrian/cyclist can be seen against the apparent exit portal

The supplementary daytime lighting as determined (sic) shall be supplied to cover the space where the restricted view occurs with a minimum luminance of $50 \%$ of that so determined using the procedures set out in Clause 3.3.

Where supplementary daytime lighting is required it shall be provided as follows:

1. Where the visibility of a critical object indicates that it will be lost against one wall or both walls then the wall only shall be illuminated to provide a background for the object to be seen in silhouette.

2. Where the visibility of a critical object indicates that it will be lost against the wall and road surface, then both the wall and road surface shall be illuminated to provide a luminance background for the object to be seen in silhouette.

2.2 Daylight contribution to lighting within the underpass

Quoting from section D 2.3 of the Australian standard [1], 
The geometry of underpasses may allow significant daylight penetration into the underpass. This condition can arise where the underpass has been assessed as Category TU3 or TU4 but the length to height ratio is less than 10 to 1, also, where the portals are wide and/or flared. Other examples include situations where underpasses are created by multiple bridges with daylight illuminated gaps. Evaluation of the day light contribution may overcome or reduce the need for daytime lighting. Utilizing the daylight contribution may significantly reduce the number of luminaires and energy consumption required for the supplementary electric lighting required to reveal a critical object.

The standard then explains how daylight analysis can be produced using a 3D model of the tunnel and surrounds and daylight modelling software operated by a competent person in order to determine the daylight contribution available. Various options are outlined depending on the amount of daylight available and the various see through and critical object view percentages. The options include reducing the lighting to $50 \%$ of the prescribed amount, providing the lighting for an hour before and after sunrise and sunset or illuminating the walls to improve contrast of the critical object. This all seems simple enough, however I have found that daylight analysis is very rarely undertaken, as the skill set required is not a stock standard product offering of the engineers who usually produce Tunnel Designs. In the case of the Deagon Deviation Underpass, a structure (named Bridge BR 21) on the north bound motorway leaving the Brisbane Airport, the Operators (Department of Transport and Main Roads, DTMR) requested a daylight analysis from the Design Engineers. As they did not have the skill set, they subcontracted me to undertake the study.

\section{CASE HISTORY BR 21}

\subsection{The original design}

In the original design of BR 21 the engineers determined the following parameters based upon the AutoCAD design drawings of the structure.

The STP was calculated with the following diagram, resulting in $38 \%$. The visibility of a critical object was shown to be obscured by the tunnel wall, therefore requiring daytime lighting. As the structure was a TU4 classification, $50 \%$ of the Lth was required.

Table 1: Input design parameters, BR 2 original design.

\begin{tabular}{|c|c|}
\hline Parameter & Value \\
\hline Tunnel width & $12.15 \mathrm{~m}$ \\
\hline Tunnel height & $6.00 \mathrm{~m}$ \\
\hline Tunnel length & $68.00 \mathrm{~m}$ \\
\hline Tunnel Carriageway & Level ground \\
\hline Design Speed & $\begin{array}{c}70 \mathrm{~km} / \mathrm{hr}(60 \\
\mathrm{km} / \mathrm{hr} \text { posted })\end{array}$ \\
\hline Safe stopping distance & $91.00 \mathrm{~m}$ \\
\hline Lth & $445 \mathrm{~cd} / \mathrm{m}^{2}$ \\
\hline Lth $(50 \%)$ & $222 \mathrm{~cd} / \mathrm{m}^{2}$ \\
\hline
\end{tabular}




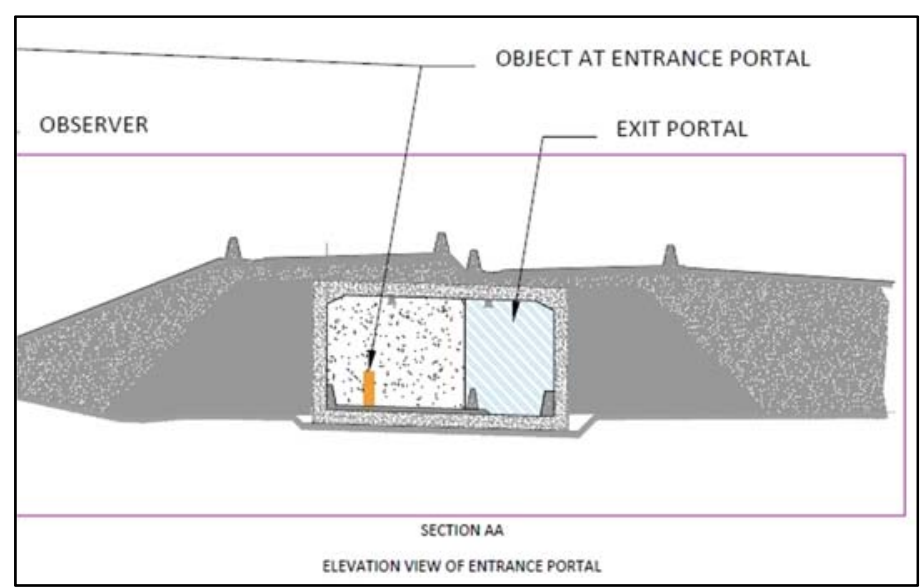

Figure 6: STP and Critical Object View diagram. The STP is calculated as $38 \%$, therefore, the tunnel is a classification TU4. (Source: construction reports.)

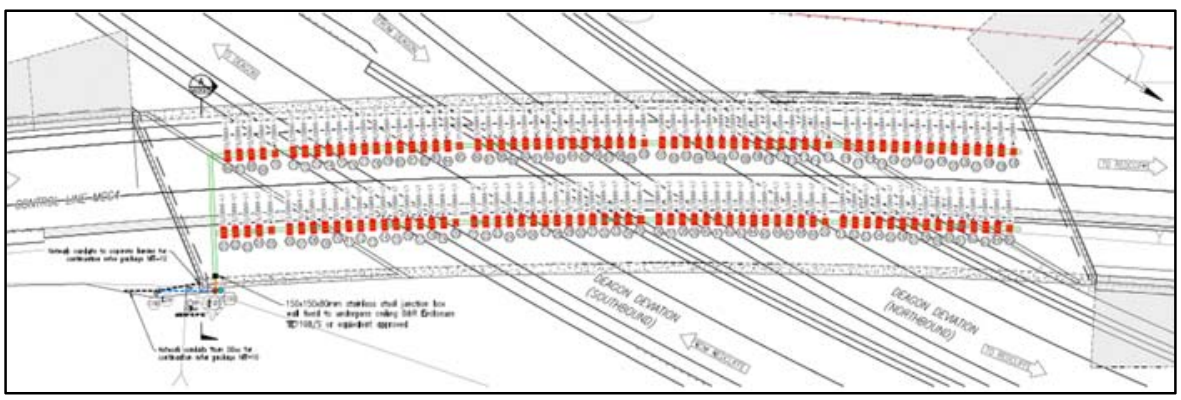

Figure 7: Construction plan view of BR 21. The two parallel rows of LED flood lights are shown in red. These are mounted with a cable ladder structure to the roof of the tunnel. (Source: Extracted by R Morrison from construction documents.)

Using the procedures prescribed in the tunnel lighting standard, the preliminary lighting layout resulted in a lighting plan of 130 LED floodlights of 230 Watts each. This quantity is the result of using the $50 \%$ of Lth method as described above. This number of light fittings consumes a power load of 29.9 kilowatts. If the daytime lighting was used for 6 hours per day, then the annual power bill would be $\$ 17,025.00$ (based on 25 cents per kilowatt hour) Apart from the electricity bill, the DTMR are also responsible for cleaning and maintaining the lighting, and this involves significant costs and traffic control. The purchase capital cost of these floodlights is $\$ 1100$ each, producing an overall purchase cost of $\$ 253,000$. The installation cost of the lighting was estimated to be $\$ 8,000$ each, resulting in an overall cost installed of $\$ 1,040,000.00$ for the $75 \mathrm{~m}$ long underpass. The amount of light provided in the tunnel by the Light Fittings when all on is 4205 lux. The amount of light on the walls is 3000 lux. Carriageway luminance was $225 \mathrm{~cd} / \mathrm{m}^{2}$. 


\subsection{Daylight analysis}

Since light fittings in tunnels are intended to provide $5-6 \%$ of the outdoor brightness it makes sense to calculate the amount of daylight penetrating the entrances in order to reduce the amount of artificial lighting installed. Rather than calculating the L20 and then designing a full lighting system to compensate, after analysing daylight availability the amount of useful daylight can be discounted from the obligation of the lighting system, effectively reducing the overall cost. Daylight analysis of the structure was carried out using the 3D Lighting Software, AGi32, from Lighting Analysis in Colorado, USA. A 3D AutoCAD model of the structure and all the surrounding geography was imported into the software and the surfaces were mapped to produce the correct reflective characteristics. AGi32 has a daylight analysis module which can calculate the amount of daylight available at any time of day at any location on the planet based upon the solar constant and local weather data. The model was set to the GPS coordinates of the structures location in Brisbane, and oriented correctly to north. Daylight calculations were then produced for a full calendar year for three days of each week (Monday, Wednesday, Friday), and 6 times of day, $(6,8,11$, am and 1, 3, $5 \mathrm{pm}$ ). The calculations were made under an overcast sky condition as this equates to the minimum available daylight. The minimum available was used in order to understand the lowest quantity of light available across the year, in other words the worst case scenario. Hundreds of calculations were produced, and the results were tabulated in Excel to create a chart for the mean minimum daylight availability.

Table 2: Luminaire schedule for the original design layout.

\begin{tabular}{|c|c|c|c|c|c|}
\hline \multicolumn{3}{|c|}{ Luminaire schedule } & \multirow{2}{*}{$\begin{array}{l}\text { Total lamp } \\
\text { lumens }\end{array}$} & & \\
\hline Symbol & Qty & Label & & LLF & Description \\
\hline 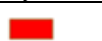 & 45 & $\mathrm{~B}$ & 37980 & 0.9 & HBW - AEC GALILEO 0F6 SS-6W 4_5-9M-3U \\
\hline a & 9 & $\mathrm{C}$ & 25800 & 0.9 & HBW - AEC GALILEO 0F6 SS-6W 4_5-6M-2U \\
\hline
\end{tabular}

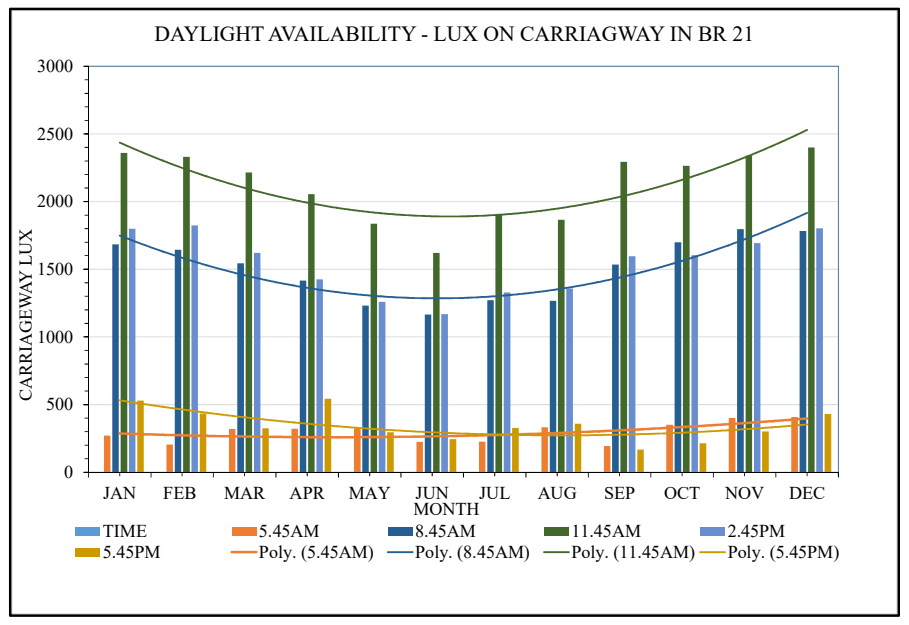

Figure 8: Chart of available daylight for a year under overcast sky. The curved lines indicate the polynomial moving average. The average for times between 8.45 am and $2.45 \mathrm{pm}$ is above 1300 lux. (Source: Daylight report to TMR by R Morrison.) 


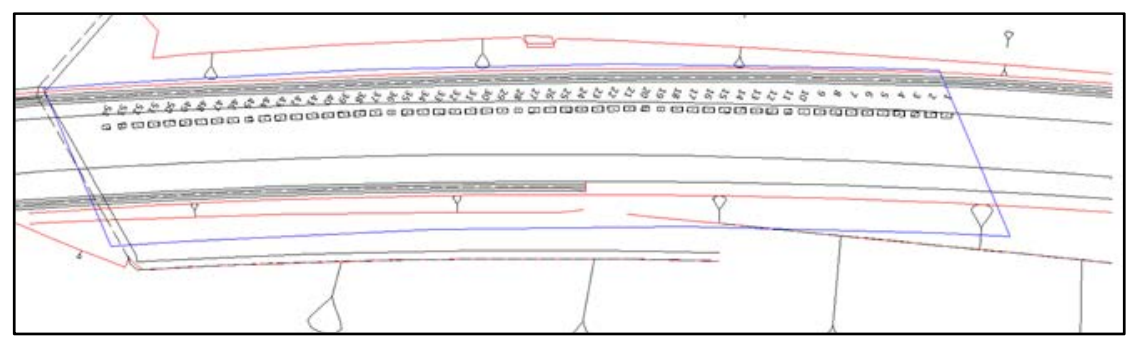

Figure 9: Construction plan of the new amended lighting layout for BR 21. The two parallel rows of LED flood lights are replaced with a single row of floodlights shown in red. (Source: Extracted by R Morrison from construction documents.)

Table 3: Luminaire Schedule for redesigned lighting after daylight analysis.

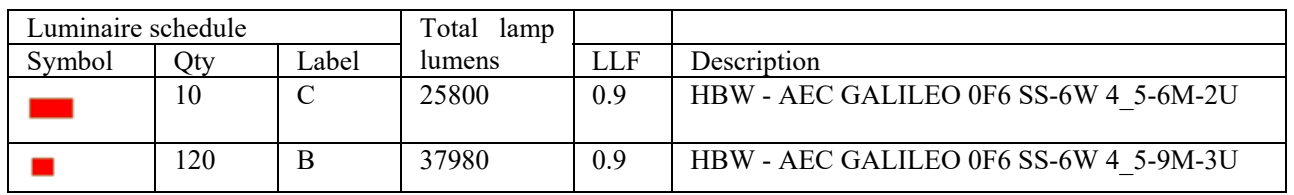

The amount of light provided in the tunnel by daylight is a minimum of 1300 lux to the carriageway. This value of light was deducted from the obligation of the lighting system, and represented a reduction of $31 \%$. The lighting layout was re-designed reducing the number of light fittings to achieve the new light technical parameters, $155 \mathrm{~cd} / \mathrm{m}^{2}(70 \%$ of original $)$.

The proposed new layout of lighting involves installing 54 LED floodlights of 230 Watts each. This number of light fittings consumes a power load of 12.42 kilowatts. If the daytime lighting was used for 6 hours per day, then the annual power bill would be $\$ 6,800.00$ (based on 25 cents per kilowatt hour) and this is a reduction of $40 \%$ in energy consumption compared to the original design. Apart from the electricity bill, the DTMR are also responsible for cleaning and maintaining the lighting, and this involves significant costs and traffic control. The purchase capital cost of these floodlights is $\$ 1100$ each, producing an overall purchase cost of $\$ 59,400$, which represents a capital saving of $\$ 193,600$. The installation cost of the lighting was estimated to be $\$ 8,000$ each, resulting in an overall cost installed of $\$ 432,000.00$ for the $75 \mathrm{~m}$ long underpass. The overall capital saving including installation was $\$ 608,000$ plus savings for electricity and maintenance.

\section{CONCLUSION}

Artificial lighting is used to increase safety in tunnels and underpasses by preventing the black hole effect. Lighting equipment is expensive to install and maintain. The arduous environment in tunnels can also reduce the lifespan of lighting equipment and associated systems. Inherent in all tunnel lighting systems is the design of photometric responses to daylight, reducing or increasing the lighting as the amount of outside daylight changes. In the case study, it is shown that a calculation of the minimum average daylight in the threshold can serve to reduce the overall commitment cost of installing artificial lighting by as much as 30\%. The usual method of installing lighting regardless of the amount of daylight only serves to increase the use of resources. These installations are then switched or dimmed 
according to the daylight outside, and the level of redundancy is high. If the lighting equipment design was reduced in accordance with the daylight available, then a reduced amount of resources would be installed, and the redundancy in the system would be low. The payback of a daylight availability study is very short, as the cost of a daylight analysis study is approximately $\$ 35,000.00$, while the capital savings are very high, $(\$ 608,000$ in the case study). The ongoing reduction in maintenance and operation costs is also a benefit to the operator. The result of the application of daylight seems at once simple and perhaps obvious, however there is little application of this knowledge in transport tunnels and underpasses. The calculative process is complex and highly specialised and time intense, however the rewards are obvious.

\section{ACKNOWLEDGEMENTS}

Department of Transport Main Roads, Queensland Australia. For permission to use case studies of their installations. Jacobs Engineering Australia, for permission to use extracts from their project documents.

\section{REFERENCES}

[1] Australian/New Zealand Standard ${ }^{\mathrm{TM}}$, AS/NZS 1158.5:2014, Lighting for roads and public spaces, Part 5: Tunnels and underpasses.

[2] The Black Hole Solution, NYX Hymera technologies, Online. http://www.nyxhemera.com/en/solution/black-hole.

[3] Kretzer, D.M., Lighting of short tunnels during daytime, Thesis for MSc: University College London, 2009.

[4] Lorphèvre, R., Deroisy, B., Deneyer, A. \& Dehon, J., R-Tech SA, Method for analysis of annual daylight levels at tunnel approach, Belgian Building Research Institute BBRI: Belgium.

[5] Du, W., Pan, X. \& Chen, F., Analysis of visual adaptability in the threshold zone of tunnels, Proceedings of the Fifth International Conference on Transportation Engineering, vol. 155, 2015.

[6] Morrison, R.A., Tunnel Lighting design: 3D modelling reduces whole of life cost. WIT Transactions on The Built Environment, vol. 128, 2012. 